\title{
Development of a Rapid Technique for the Evaluation of the Response of Brassica napus to Verticillium wilt
}

\author{
L. A. Steventon, Department of Plant Biology, Swedish University of Agricultural Sciences, Box 7080, S-750 07 \\ Uppsala, Sweden; I. Happstadius, Svalöf Weibull AB, S-268 81 Svalöv, Sweden; P. Okori, and C. Dixelius, De- \\ partment of Plant Biology, Swedish University of Agricultural Sciences, Box 7080, S-750 07 Uppsala, Sweden
}

\begin{abstract}
Steventon, L. A., Happstadius, I., Okori, P., and Dixelius, C. 2002. Development of a rapid technique for the evaluation of the response of Brassica napus to Verticillium wilt. Plant Dis. 86:854-858.

Extensive efforts are being made to develop oilseed rape cultivars with resistance to Verticillium wilt. Evaluation of these cultivars involves either dipping roots of young plants in a conidial suspension followed by replanting in soil, or sowing the seed directly in artificially infested soil. These methods for screening for resistance take a long time and are expensive. The objective of this research was to develop a rapid and reliable method of screening cultivars for resistance to Verticillium wilt. A box test method in which 4-day-old seedlings were inoculated and grown under sterile conditions in double magenta boxes was developed. The Brassica napus cultivars Accord, Express, Hanna, and Libraska were inoculated with isolates of Verticillium longisporum or $V$. dahliae. The results from the box test method were compared with root-dip inoculation of seedlings grown in a soil mixture under greenhouse conditions. In addition, plants from the box test were randomly selected and transferred to pots containing sterile soil to permit comparison of plants from the box test at similar developmental stage with plants in the root-dip method. Disease evaluation was based on the number of days after transferring seedlings into the boxes that root browning, root and shoot blackening, and wilting of cotyledons developed. Additional disease evaluation was based on a 0 to 5 disease severity scale based on the percentage of wilted leaves (number) and/or the percentage of stunting (mm) of inoculated plants compared with noninoculated plants. Disease severity was higher on Hanna than on Express, and isolates of $V$. longisporum were more virulent than isolates of $V$. dahliae. There was a significant correlation $(r=0.93)$ of disease rating between the traditional root-dip method and the new box test method. Analysis of variance revealed that the interaction between cultivars and isolates was highly significant $(P \leq 0.01)$, whereas method of inoculation did not affect the results. In the box test, plants were rated after 25 days, which is at least 3.5 times more rapid than the root-dip method.
\end{abstract}

chlorotic patches between the veins, and the veins become dark and distinct. Plants infected early in the growing season often are stunted and contain microsclerotia on or inside the stem (3).

Extensive efforts are being made to develop oilseed rape cultivars with resistance. Evaluation of cultivars involves either dipping roots of young plants in a conidial suspension followed by replanting in soil $(1,5,14)$, or sowing the seed directly in artificially infested soil $(2,15)$. In both methods, plants are rated for disease symptoms at the adult stage, 8 to 12 weeks after initiation of the experiments, using rating schemes based on plant chlorosis, stem and vascular discoloration, foliar wilting, stunting of plants, and dry weight of shoots and roots. These methods of screening for resistance are long and expensive. The objective of this research was to develop a rapid and reliable method of screening cultivars for resistance to Verticillium wilt.

\section{MATERIALS AND METHODS}

Cultivars of $B$. napus and isolates of Verticillium. The B. napus cultivars Accord, Express, Hanna, and Libraska were
Brassica oilseed production has become one of the most important sources of vegetable oils for human consumption (6). Other non-nutritive oils are valuable sources of industrial chemicals, fuel, and oilseed rape (Brassica napus L.) meal that is used for livestock feeding $(9,10)$. In northern Europe, Verticillium wilt $(8,16,18)$, caused by a group of isolates of Verticillium dahliae renamed $V$. longisporum $(5,12,13,17)$, limits the production of oilseed rape. Plants become infected through the roots by direct penetration of the epidermal cells or through open wounds via conidia (12). The fungus enters the vascular system and moves in the xylem vessels causing wilting or, in later stages, premature ripening of the seed. Foliar symptoms are often observed as

Corresponding author: C. Dixelius

E-mail: Christina.Dixelius@vbiol.slu.se

Accepted for publication 5 April 2002.

Publication no. D-2002-0528-06R

(C) 2002 The American Phytopathological Society
Table 1. Origin of the isolates of Verticillium longisporum and V. dahliae that were evaluated in the box test inoculation experiments

\begin{tabular}{|c|c|c|c|c|c|}
\hline Isolate $^{a}$ & $\begin{array}{l}\text { Country of } \\
\text { origin }\end{array}$ & Host & Isolate $^{\mathrm{a}}$ & $\begin{array}{l}\text { Country of } \\
\text { origin }\end{array}$ & Host \\
\hline \multicolumn{3}{|c|}{ V. longisporum } & \multicolumn{3}{|l|}{ V. dahliae } \\
\hline VD1 & Sweden & Brassica napus & CBS1 & Netherlands & Solanum tuberosum \\
\hline VD2 & Sweden & Brassica napus & CBS2 & Netherlands & Antirrhinum majus \\
\hline VD4 & Sweden & Brassica napus & CBS3 & Unknown & Humulus lupulus \\
\hline VD6 & Sweden & Brassica napus & CBS4 & Netherlands & Lycopersicon \\
\hline VD11 & Sweden & Brassica napus & & & esculentum \\
\hline VD12 & Sweden & Brassica napus & VD17 & Germany & Trifolium pratense \\
\hline VD13 & Sweden & Brassica napus & VD20 & Argentina & Helianthus annuиs \\
\hline VD18 & Germany & Brassica napus & VD21 & Argentina & Helianthus annuus \\
\hline $36-1$ & Sweden & Brassica napus & VD22 & Argentina & Helianthus annuus \\
\hline $37-1$ & Sweden & Brassica napus & INRA544 & France & Brassica napus \\
\hline $39-3$ & Sweden & Brassica napus & INRA591 & France & Brassica napus \\
\hline $40-2$ & Sweden & Brassica napus & INRA617 & France & Brassica napus \\
\hline $42-1$ & Sweden & Brassica napus & NOVA1 & France & Beta vulgaris \\
\hline $43-3$ & Sweden & Brassica napus & NOVA2 & Sweden & Beta vulgaris \\
\hline $44-4$ & Sweden & Brassica napus & NOVA4 & France & Beta vulgaris \\
\hline $\mathrm{CV} 3$ & Sweden & Brassica napus & & & \\
\hline V10 & Germany & Brassica napus & & & \\
\hline V33 & Germany & Brassica napus & & & \\
\hline
\end{tabular}

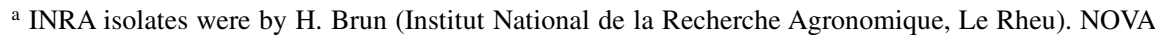
isolates were provided by M. Nihlgaard (Novartis, Landskrona). Isolates V10 and V33 were provided by G. Wolf (University of Göttingen) and isolate CV3 was provided by C. Svensson (SLU, Uppsala). The CBS prefixed isolates were obtained from the Centraalbureau voor Schimmelcultures, the Netherlands, and correspond to following numbers: CBS1 $=384.49$, CBS2 $=388.49$, CBS3 $=389.49$, and CBS4 $=177.66$. All other isolates were provided by I. Happstadius (Svalöf Weibull AB, Svalöv). 
used in the study. The cultivar Express exhibits a field tolerance to Verticillium infection and is used as a reference in national variety trials. Accord, Hanna, and Libraska are susceptible varieties.

Thirty-two isolates of Verticillium were included in the box test (Table 1). Sixteen of these isolates were collected from fields of oilseed rape from different regions of Sweden, and three isolates each from France (INRA series) and Germany isolated from B. napus were included. Eleven isolates were collected from other host species in Sweden and other countries. The identification of isolates as either $V$. dahliae or $V$. longisporum was based on molecular and morphological characteristics (13). All isolates used were cultured from single spores and grown on potato dextrose agar (Difco Laboratories, Detroit, MI) or malt extract agar (Difco) plates in the dark at 18 to $22^{\circ} \mathrm{C}$. To maintain pathogenicity, the isolates were inoculated onto oilseed rape plants and reisolated every 7 weeks. Isolates were cultured on agar slants at $4^{\circ} \mathrm{C}$ and in glycerol at -20 or $-70^{\circ} \mathrm{C}$ for longterm storage.

Box test inoculation method. The boxes were prepared 3 days prior to plant inoculation. Fifty milliliters of Murashige and Skoog (MS) medium (ICN Biomedicals, Inc., Aurora, $\mathrm{OH}$ ) augmented with $1 \%$ (wt/vol) sucrose (MS-1) and solidified with $3 \mathrm{~g}$ of gelrite per liter (Merck and Co., Rahway, NJ) was added to double magenta boxes (Sigma-Aldrich AB, St. Louis, MO). A conidial suspension of each Verticillium isolate was prepared and adjusted to $1.6 \times$ $10^{6}$ conidia per $\mathrm{ml}$ using sterile distilled water. Five hundred microliters of the suspension was added to the box and spread with a glass rod to provide a uniform layer of conidia. Control boxes were prepared using sterile distilled water. The boxes were incubated in the dark at 18 to $22^{\circ} \mathrm{C}$. Seeds of the oilseed rape cultivars were surface-sterilized by agitating in $0.525 \%$ $\mathrm{NaOCl}$ for $1 \mathrm{~h}$. Seeds were then dipped for $1 \mathrm{~min}$ in $70 \%$ ethanol, followed by three washes in sterile distilled water. The seeds were germinated on petri dishes containing sterile MS-1 media incubated at $22^{\circ} \mathrm{C}$ with a 16-h photoperiod for 4 days. Seedlings were transferred to the magenta boxes (one seedling per box) under sterile conditions. Care was taken to position each plant in the center of the box in an upright position, so that only the base of the stem and the roots were in direct contact with the pathogen. The completed boxes (Fig. 1) were then placed in a growth chamber with a 16 -h photoperiod (light intensity $200 \mu \mathrm{E} \cdot \mathrm{m}^{-2} \cdot \mathrm{s}^{-1}$ ) at $18^{\circ} \mathrm{C}$ (dark) to $22^{\circ} \mathrm{C}$ (light). Disease progression was followed by recording the number of days after being placed in the boxes that the following symptoms developed: (i) discoloration of the roots (Fig. 2A), (ii) blackening seen on the lowest part of the stem due to the production of microscle- rotia (Fig. 2B and C), and (iii) chlorosis and necrosis of the cotyledons (Fig. 2D and $\mathrm{E}$ ).

After 25 days, disease severity of each plant was rated based on the percentage of wilted leaves and/or the percentage of stunting $(\mathrm{mm})$ compared with the number of wilted leaves and average height of control plants where $0=$ no symptoms, $1=$ wilting and/or stunting $<25 \%, 2=$ wilting and/or stunting 25 to $50 \%, 3=$ wilting and/or stunting 51 to $90 \%, 4=$ wilting and/or stunting $\geq 90 \%$, and $5=$ dead plant (Fig. 3).

After completing the disease severity rating, eight plants per cultivar and isolate were randomly chosen from the box test and transferred to pots containing soil and grown in a greenhouse (18-h photoperiod, at 15 to $23^{\circ} \mathrm{C}$ ) for 7 weeks. This procedure

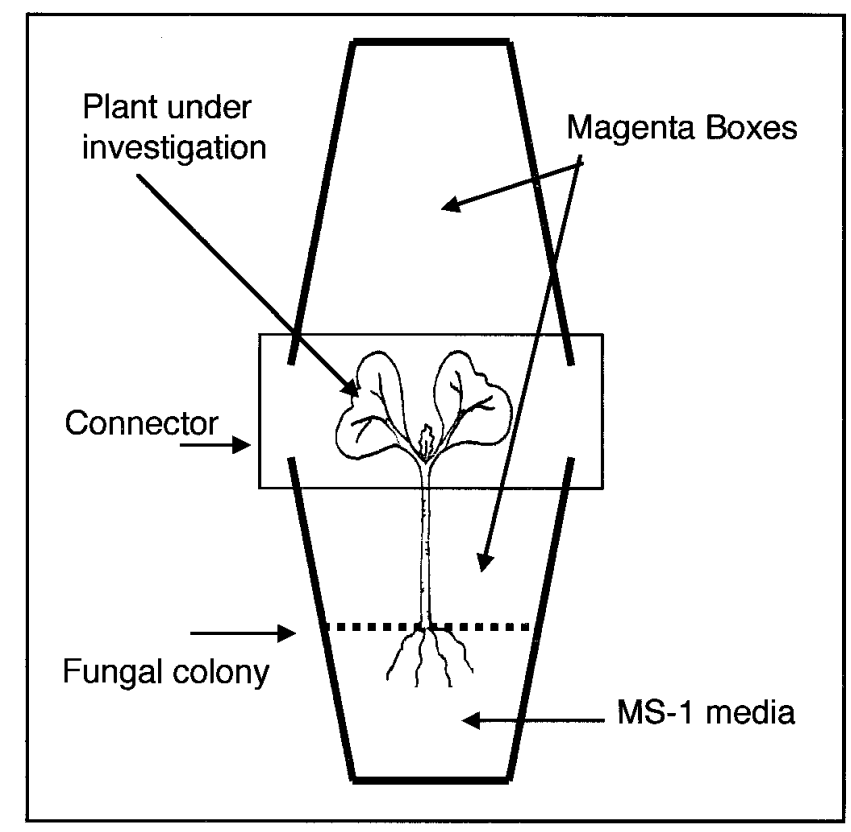

Fig. 1. Diagram of the double magenta boxes used in the box test study.

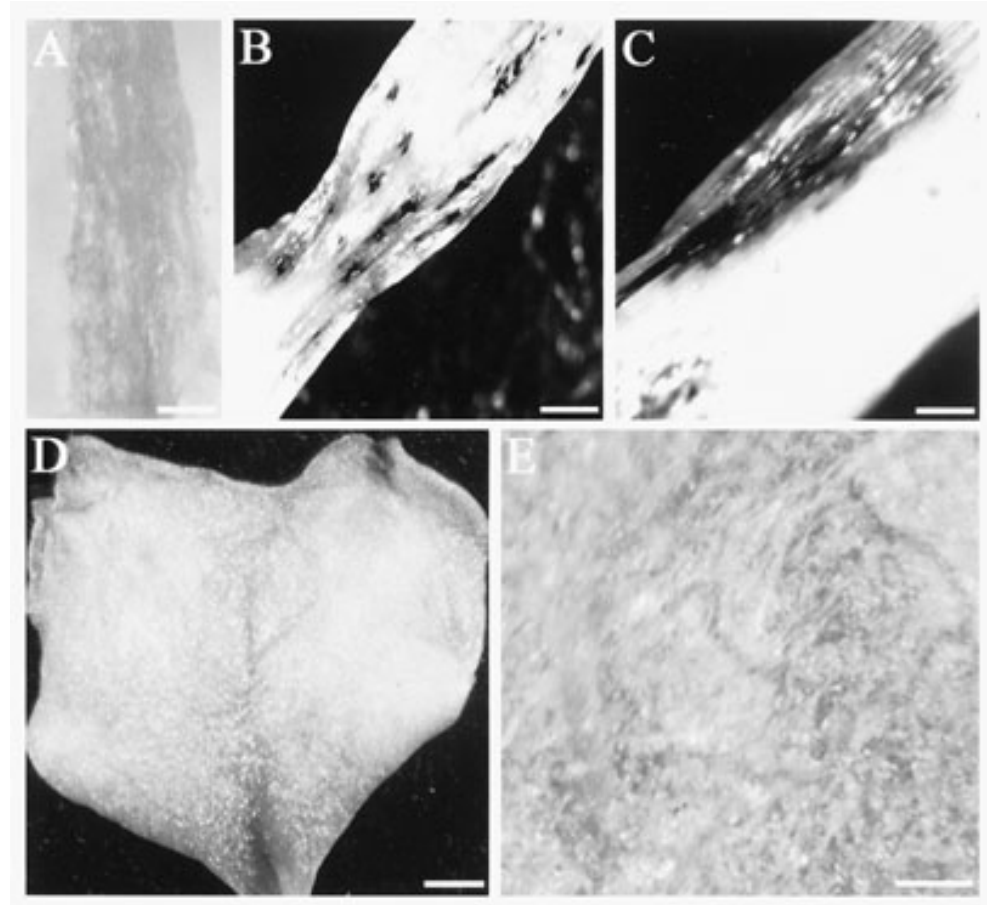

Fig. 2. Disease symptoms on Brassica napus cv. Hanna and cv. Express seedlings after inoculation with isolate VD1 of Verticillium longisporum. A, root browning, bar $=1 \mathrm{~mm} ; \mathbf{B}$, blackening at root $/$ shoot interface, bar $=2 \mathrm{~mm}$; $\mathbf{C}$, blackening on stem, bar $=0.6 \mathrm{~mm} ; \mathbf{D}$, premature yellowing (chlorosis) of infected cotyledon, bar $=3 \mathrm{~mm}$; $\mathbf{E}$, darkening of veins on an infected cotyledon, bar = $0.4 \mathrm{~mm}$. 


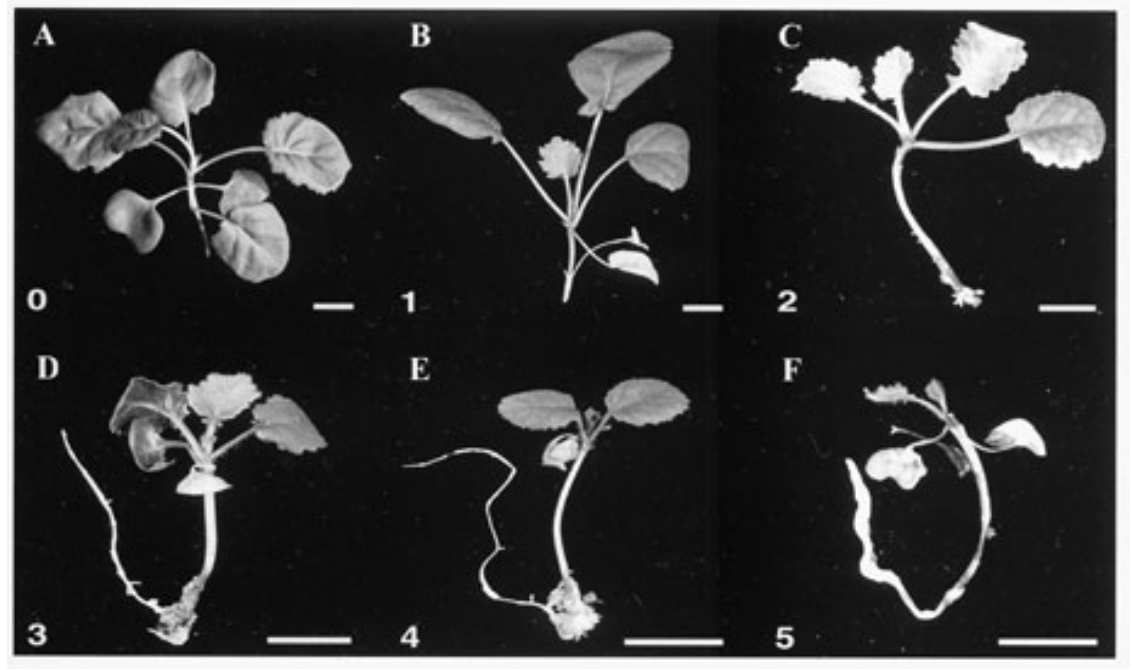

Fig. 3. Illustration of the scale used to record pathogenicity of Brassica napus plants of cv. Hanna 25 days after inoculation with isolates of Verticillium longisporum. Plants were rated on a scale of 0 to 5 (shown in the bottom left-hand corner of each photograph): A, symptomless plant; B, wilting and/or stunting <25\%; C, wilting and/or stunting 25 to $50 \%$; $\mathbf{D}$, wilting and/or stunting 51 to $90 \%$; $\mathbf{E}$, wilting and $/$ or stunting $>90 \% ; \mathbf{F}$, dead plant. Bar $=1 \mathrm{~cm}$. permitted a comparison between plants from the box test and plants inoculated using the root-dip method.

Root-dip inoculation method. One or two seeds of each cultivar were planted in small pots containing sterilized soil and covered with sand. After germination, the seedlings were thinned to one plant per pot. The pots were placed into plastic containers and maintained in a greenhouse with a $16-\mathrm{h}$ photoperiod at 15 to $18^{\circ} \mathrm{C}$. After the development of the first true leaves (approximately 14 days), seedlings were inoculated according to Koike et al (7). Only isolates VD1, VD17, V10, and $\mathrm{V} 33$ of $V$. longisporum and isolates V22 and INRA544 of $V$. dahliae were used in this test. Plants were maintained in a greenhouse with 16 -h photoperiod at $20^{\circ} \mathrm{C}$ for 8 to 10 weeks. When 80 to $90 \%$ of the susceptible cultivar had wilted, the plants were rated using the 0 to 5 scale described previously for the box test.

Statistical analysis. Experiments were set up to compare the three inoculation

Table 2. Disease progression and disease severity ratings on Brassica napus cultivars Hanna and Express inoculated with isolates of Verticillium longisporum and V. dahliae

\begin{tabular}{|c|c|c|c|c|c|c|c|c|}
\hline \multirow[b]{3}{*}{ Isolate } & \multicolumn{6}{|c|}{ Days $^{\mathbf{a}}$} & & \\
\hline & \multicolumn{2}{|c|}{ Root browning } & \multicolumn{2}{|c|}{ Root/shoot blackening } & \multicolumn{2}{|c|}{ Cotyledon necrosis } & \multicolumn{2}{|c|}{ Disease severity ${ }^{b}$} \\
\hline & Hanna & Express & Hanna & Express & Hanna & Express & Hanna & Express \\
\hline \multicolumn{9}{|c|}{ V. longisporum } \\
\hline VD1 & 4.0 & 6.0 & 4.2 & 5.6 & 9.2 & 11.5 & 3.6 & 2.2 \\
\hline VD2 & 5.6 & 7.3 & 4.6 & 6.3 & 9.8 & 11.1 & 3.3 & 2.1 \\
\hline VD4 & 3.3 & 5.2 & 3.7 & 5.1 & 8.7 & 11.7 & 3.5 & 1.8 \\
\hline VD6 & 4.5 & 5.3 & 4.7 & 5.2 & 9.3 & 10.2 & 3.7 & 2.0 \\
\hline VD11 & 5.0 & 5.7 & 3.8 & 4.7 & 8.8 & 10.6 & 3.4 & 1.9 \\
\hline VD12 & 5.7 & 7.1 & 3.8 & 5.4 & 10.5 & 12.1 & 3.2 & 1.5 \\
\hline VD13 & 6.3 & 8.5 & 3.7 & 5.2 & 9.7 & 11.2 & 3.5 & 2.3 \\
\hline VD18 & 6.2 & 7.5 & 4.2 & 5.3 & 9.9 & 10.8 & 3.2 & 2.0 \\
\hline $36-1$ & 3.8 & 7.6 & 2.9 & 5.4 & 8.8 & 9.5 & 3.8 & 1.9 \\
\hline $37-1$ & 3.3 & 6.5 & 2.8 & 4.3 & 7.2 & 10.3 & 4.1 & 2.1 \\
\hline $39-3$ & 3.5 & 7.8 & 3.5 & 5.1 & 9.5 & 11.8 & 3.3 & 1.4 \\
\hline $40-2$ & 2.9 & 6.1 & 2.8 & 3.9 & 8.5 & 10.3 & 3.4 & 1.5 \\
\hline $42-1$ & 3.5 & 7.3 & 2.5 & 4.5 & 8.0 & 10.9 & 3.7 & 1.6 \\
\hline $43-3$ & 4.0 & 5.8 & 2.3 & 4.3 & 9.9 & 11.3 & 3.8 & 1.7 \\
\hline $44-4$ & 2.4 & 5.3 & 3.6 & 5.0 & 10.2 & 15.0 & 3.6 & 1.5 \\
\hline CV3 & 4.6 & 5.9 & 3.4 & 4.8 & 5.3 & 6.5 & 5.3 & 2.2 \\
\hline V10 & 5.8 & 6.9 & 3.9 & 4.9 & 9.4 & 13.7 & 4.4 & 2.4 \\
\hline V33 & 4.3 & 6.1 & 3.8 & 5.0 & 9.0 & 11.8 & 4.5 & 2.8 \\
\hline $\operatorname{LSD}^{\mathrm{c}}$ & 1.8 & 1.2 & 1.1 & 0.9 & 1.5 & 2.6 & 0.9 & 0.6 \\
\hline \multicolumn{9}{|l|}{ V. dahliae } \\
\hline VD17 & 9.7 & 0.9 & 9.2 & 11.0 & 9.3 & 12.3 & 1.9 & 0.8 \\
\hline VD20 & 9.3 & 11.3 & 8.0 & 10.5 & 10.9 & 13.7 & 1.7 & 1.2 \\
\hline VD21 & 8.5 & 10.9 & 8.5 & 9.9 & 9.6 & 11.2 & 2.1 & 1.3 \\
\hline VD22 & 9.1 & 10.7 & 8.7 & 10.2 & 10.1 & 12.9 & 0.9 & 0.8 \\
\hline INRA544 & 8.2 & 10.3 & 9.1 & 11.0 & 11.0 & 13.2 & 1.9 & 1.1 \\
\hline INRA591 & 7.5 & 9.9 & 9.2 & 11.1 & 11.3 & 13.3 & 1.7 & 1.2 \\
\hline INRA617 & 9.6 & 11.8 & 8.9 & 9.5 & 9.4 & 13.7 & 1.6 & 1.5 \\
\hline CBS1 & 8.8 & 10.3 & 9.5 & 11.7 & 10.8 & 14.5 & 1.9 & 0.7 \\
\hline CBS2 & 8.5 & 9.4 & 7.5 & 9.8 & 12.1 & 15.0 & 2.1 & 1.6 \\
\hline CBS3 & 8.7 & 10.4 & 8.5 & 9.0 & 11.8 & 14.8 & 1.8 & 0.7 \\
\hline CBS4 & 9.2 & 10.3 & 8.3 & 9.7 & 12.2 & 15.3 & 2.2 & 1.3 \\
\hline NOVA1 & 9.4 & 11.2 & 9.0 & 10.3 & 12.0 & 16.8 & 1.7 & 1.0 \\
\hline NOVA2 & 8.5 & 10.1 & 8.9 & 10.5 & 11.8 & 17.1 & 2.0 & 1.2 \\
\hline NOVA4 & 7.4 & 9.2 & 8.5 & 9.7 & 9.3 & 14.9 & 2.3 & 1.8 \\
\hline LSD & 1.0 & 1.1 & 0.9 & 1.2 & 1.2 & 2.7 & 0.6 & 0.5 \\
\hline
\end{tabular}

${ }^{a}$ Values are the mean number of days for the described symptom to first appear after seedlings were placed in the magenta boxes.

b The final rating of each plant 25 days after seedlings were placed in the magenta boxes inoculated with Verticillium spp. based on the percentage of wilted leaves (number) and/or the percentage of stunting $(\mathrm{mm})$ compared with noninoculated plants where $0=$ no symptoms, $1=$ wilting and/or stunting $<25 \%, 2=$ wilting and/or stunting 25 to $50 \%, 3=$ wilting and/or stunting 51 to $90 \%, 4=$ wilting and/or stunting $>90 \%, 5=$ dead plant.

${ }^{\mathrm{c}}$ Least significant difference (LSD) was calculated at $P \leq 0.05$. 
methods: the box test, root dipping, and the transfer of inoculated plants from the boxes to soil. Treatments were arranged in a randomized complete block with three replications. Each replicate consisted of 15 plants per cultivar. Each cultivar was inoculated with each of 32 Verticillium isolates. Fifteen uninoculated plants of each cultivar were used as controls. Student's $t$ test, Pearson correlation analysis, and analysis of variance were calculated by using PROC GLM (SAS Institute, Cary, NC). Differences among means were tested using Fisher's least significant difference (LSD).

Costs for materials, labor, greenhouse space (including electricity), growth chambers, and cleaning were recorded to compare total costs for the box test and the root-dip method.

\section{RESULTS}

Box test inoculation. Disease severity on cultivars Express and Hanna caused by each of the 32 isolates of Verticillium are presented in Table 2. Root browning and blackening of the shoot occurred earlier $(P$ $\leq 0.01$ ) than chlorosis of the cotyledons for both cultivars. The discoloration of roots and stems also appeared earlier $(P \leq 0.01)$ with isolates of $V$. longisporum compared with isolates of $V$. dahliae. Disease severity 25 days after inoculation with either $V$. dahliae or $V$. longisporum was significantly higher on Hanna than on Express $(P<0.05)$, and disease severity was higher on plants inoculated with $V$. longisporum than on plants inoculated with $V$. dahliae $(P<0.01)$.

Comparisons between inoculation methods. Differences in disease ratings among cultivars and isolates of Verticillium and the interaction between cultivars and isolates were all significant $(P \leq 0.01)$, but differences in ratings among methods of inoculation were not significant (Table 3 ). Based on disease indices on plants from the root-dip, box tests, and plants transferred from the boxes, the isolates of $V$. longisporum were more virulent than the isolates of $V$. dahliae, and the cultivar Express had lower disease severity than Accord and Libraska (Table 4). Disease indices between the box test and root-dip methods $(r=0.93)$, between the root-dip method and the transferred plants $(r=$ 0.78 ), and between the box test and transferred plants $(r=0.72)$ were all significantly correlated.

The cost was $61 \%$ lower per plant using the box test compared with the root-dip method (4.58 versus 11.74 Skr). Electricity to operate the greenhouse and cost of cleaning the greenhouse space, which was necessary to avoid contamination of other Brassica experiments, contributed to the higher cost of the root-dip method.

\section{DISCUSSION}

The box test method described here is useful for rapid evaluation of the suscepti- bility of cultivars of $B$. napus and the virulence of $V$. dahliae and $V$. longisporum. Disease symptoms developed earlier and were more severe on the susceptible cv. Hanna compared with the more tolerant cv. Express. V. longisporum isolates were more virulent than $V$. dahliae on $B$. napus. Isolates of $V$. dahliae from other host species were also able to infect $B$. napus. In a related study, isolates of $V$. dahliae from other hosts readily infected $B$. oleracea plants but were less virulent compared with isolates from $B$. oleracea (14). Cultivars of B. napus and $B$. oleracea can be infected by isolates of Verticillium originating from other plant species, although a more specific response to $B$. napus has been reported (5).

Table 3. Analysis of variance of disease ratings on Brassica napus cultivars inoculated with isolates of Verticillium spp. using three evaluation methods

\begin{tabular}{lccc}
\hline Source & df & Mean square & $\boldsymbol{F}$ value $^{\mathbf{a}}$ \\
\hline Cultivar & 2 & 84.92 & $25.31^{* *}$ \\
Replicate & 2 & 2.75 & 1.06 \\
Verticillium isolates & 5 & 403.39 & $8.98^{*}$ \\
Evaluation method & 1 & 342.62 & 26.82 \\
Cultivars $\times$ isolates & 10 & 10.24 & $3.04^{* *}$ \\
Cultivars $\times$ methods & 2 & 8.76 & 0.57 \\
Cultivars $\times$ isolates $\times$ methods & 10 & 241.04 & 0.94 \\
\hline
\end{tabular}

a Values followed by $*$ and $* *$ are statistically significant at $P \leq 0.05$ and $P \leq 0.01$, respectively.

Table 4. Mean disease indices for the three evaluation methods on three cultivars of Brassica napus inoculated with six isolates of Verticillium

\begin{tabular}{llccc}
\hline \multirow{3}{*}{ Cultivar } & & \multicolumn{3}{c}{ Disease index $^{\mathbf{a}}$} \\
\cline { 3 - 5 } Express & Isolate $^{\mathbf{b}}$ & Root-dip $^{\mathbf{c}}$ & Box test $^{\mathbf{c}}$ & Plant transfer $^{\mathbf{d}}$ \\
& VD1 & 2.0 & 2.3 & 2.1 \\
& VD13 & 2.4 & 2.2 & 2.2 \\
& V10 & 2.1 & 2.4 & 2.2 \\
& V33 & 2.4 & 2.5 & 2.4 \\
& Mean & 2.2 & 2.4 & 2.2 \\
& INRA544 & 1.4 & 1.3 & 1.1 \\
Accord & VD22 & 1.1 & 1.0 & 1.0 \\
& Mean & 1.3 & 1.2 & 1.1 \\
& VD1 & 3.9 & 3.7 & 4.6 \\
& VD13 & 4.1 & 3.6 & 4.5 \\
& V10 & 4.9 & 4.8 & 4.9 \\
& V33 & 4.0 & 4.7 & 4.0 \\
& Mean & 4.2 & 4.2 & 4.5 \\
& INRA544 & 1.6 & 2.0 & 2.2 \\
& VD22 & 1.1 & 1.2 & 1.8 \\
& Mean & 1.4 & 1.6 & 2.0 \\
& VD1 & 4.1 & 4.3 & 4.6 \\
& VD13 & 4.3 & 4.4 & 4.9 \\
& V10 & 3.6 & 3.8 & 4.4 \\
& V33 & 3.5 & 4.0 & 4.5 \\
& Mean & 3.9 & 4.1 & 4.6 \\
& INRA544 & 1.8 & 1.6 & 1.9 \\
& VD22 & 1.7 & 1.4 & 2.0 \\
& Mean & 1.8 & 1.5 & 2.0 \\
\hline
\end{tabular}

${ }^{a}$ Final rating of each plant 25 days after seedlings were placed in the magenta boxes inoculated with Verticillium spp. based on the percentage of wilted leaves (number) and/or the percentage of stunting $(\mathrm{mm})$ compared with noninoculated plants where $0=$ no symptoms, $1=$ wilting and/or stunting $<25 \%, 2$ = wilting and/or stunting 25 to $50 \%, 3=$ wilting and/or stunting 51 to $90 \%, 4=$ wilting and/or stunting $>90 \%, 5=$ dead plant.

${ }^{\mathrm{b}} \mathrm{VD1}$, VD13, V10, and V33 are V. longisporum; INRA544 and VD22 are V. dahliae.

${ }^{\mathrm{c}} \mathrm{n}=45$ plants.

$\mathrm{d} \mathrm{n}=8$ plants. (he close length polymorphism (AFLP) analysis has shown that the isolates included in this investigation and isolates from $B$. oleracea to the $V$. longisporum species (4). Three (INRA544, INRA591, and the same phylogenetic group and had significantly smaller spore size and nuclear lium from B. napus (13). These three isosimilar to that of the $V$. dahliae isolates.

One of the most common methods of inoculation of plant seedlings is the root-dip
The ability of isolates of Verticillium to
cause similar symptoms on B. napus and $B$.

useful for rapid evaluation of the suscepti- 
method whether it is done on intact or injured roots. Koike et al. (7) compared dipping the roots, cutting the roots prior to dipping, injecting the stem with a conidial suspension, and positioning an agar block covered with the fungus in soil surrounding the roots for the inoculation of cauliflower plants. Their research indicated that the root-dip method gave the most consistent results in repeated experiments. The results from the box test in this study were highly correlated with the root-dip method, which indicates that the box test can be used as an alternative to the rootdip method. The box test method also was less expensive, but costs will depend on available facilities, equipment, and local costs for electricity.

The box test also allows for a two stage pathogenicity test in a similar length of time required for the root-dip method. Putative resistance can be demonstrated on inoculated plants after 25 days in the box test, and again on mature plants after transplanting into pots. By doing this, the initial stages of the infection can be recorded, and highly susceptible plants eliminated at an early stage. Resistant plants can then be allowed to continue to grow under greenhouse conditions for evaluation as mature plants. This evaluation will also permit the development of seeds for testing progeny. This approach will be of interest when a limited amount of seed exists, such as in the evaluation of newly resynthesized $B$. napus genotypes in which the resistance to Verticillium wilt is being introduced from $B$. oleracea.

\section{ACKNOWLEDGMENTS}

We thank J. Fahleson for assistance with the isolate culturing, G. Swärdh for technical assistance, and E. Mäntylä for photographical assistance. The work was funded by the EU (FAIR CT97-3509) program, the Swedish Seed and Oilseed Growers Association, and the Swedish Council for Forestry and Agricultural Research.

\section{LITERATURE CITED}

1. Bhat, R. G., and Subbarao, K. V. 1999. Host range specificity in Verticillium dahliae. Phytopathology 89:1218-1225.

2. Chang, R. J., and Eastburn, D. M. 1994. Host range of Verticillium dahliae from horseradish and pathogenicity of strains. Plant Dis. 78:503-506.

3. Heale, J. B., and Karapapa, V. K. 1999. The verticillium threat to Canada's major oilseed crop: Canola. Can. J. Plant Pathol. 21:1-7.

4. Hu, Q., Fahleson, J., and Dixelius, C. 2001. Molecular and morphological variation of Verticillium isolates from Brassica napus. Page 39 in: Proc. Int. Verticillium Sympos. 8th.

5. Karapapa, V. K., Bainbridge, B. W., and Heale, J. B. 1997. Morphological and molecular characterization of Verticillium longisporum comb. Nov., pathogenic to oilseed rape. Mycol. Res. 101:1281-1294.

6. Kimber, D. S., and McGregor, D. I. 1995. The species and their origin, cultivation and world production. Pages 1-7 in: Brassica Oilseeds. Production and Utilization. D. Kimber and K. I. McGregor, eds. CAB International, Cambridge, UK.

7. Koike, S. T., Subbarao, K. V., Davis, R. M., Gordon, T. R., and Hubbard, J. C. 1994. Verticillium wilt of cauliflower in California. Plant Dis. 78:1116-1121.

8. Krüger, W. von. 1989. Unterschungen zur Verbreitung von Verticillium dahliae Kleb. und anderen Krankheits und Schaderregerm bei Raps in der Bundesrepublik Deutschland. Nachrbl. Dtsch. Pflanzenschutzd. 41:49-56.

9. Murphy, D. J. 1996. Engineering oil produc- tion in rapeseed and other crops. Tibtech 14:206-213.

10. Rosa, E. A. S. 1999. Chemical composition. Pages 315-357 in: Biology of Brassica Coenospecies. C. Gómez-Campo, ed. Elsevier, Amsterdam, Netherlands.

11. Schnathorst, W. C. 1981. Life cycle and epidemiology of Verticillium. Pages 81-111 in Fungal Wilt Diseases of Plants. M. E. Mace, A. A. Bell, and C. H. Bechman, eds. Academic Press, London.

12. Stark, C. 1961. Das Auftreten der Verticillium-Tracheomykosen in Hamburger Gartenbaukulturen. Gartenbauwissenschaft 26:493528.

13. Steventon, L. A., Fahleson, J., Hu, Q., and Dixelius, C. 2002. Identification of the causa agent of Verticillium wilt of winter oilseed rape in Sweden as Verticillium longisporum. Mycol. Res. 106:1-8.

14. Subbarao, K. V., Chassot, A., Gordon, T. R., Hubbard, J. C., Bonello, P., Mullin, R., Okamoto, D., Davis, R. M., and Koike, S. T. 1995. Genetic relationships and cross pathogenicities of Verticillium dahliae isolates from cauliflower and other crops. Phytopathology 85:1105-1112.

15. Subbarao, K. V., and Hubbard, J. C. 1996. Interactive effects of broccoli residue and temperature on Verticillium dahliae microsclerotia in soil and on wilt in cauliflower. Phytopathology 86:1303-1310.

16. Svensson, C, and Lerenius, C. 1987. An investigation on the effect of Verticillium wilt (Verticillium dahliae Kleb.) on oilseed rape Int. Org. Biol. Control Bull. 10:30-34.

17. Zeise, K., and Tiedemann, A. 2001. Morphological and physiological differentiation among vegetative compatibility groups of Verticillium dahliae and V. longisporum. J. Phytopathol. 149:469-475.

18. Zielenski, D., and Sadowski, C. 1995. A preliminary study on Verticillium dahliae Kleb. in winter oilseed rape in Poland. Pages 649-651 in: Proc. Int. Rapeseed Congr. 9th. 